ment in the prediction of overall fruit mass accretion were obtained by $\mathrm{GA}_{\text {Gossym }}$. Running $\mathrm{GA}_{\text {Gossym }}$ with the full parameter set resulted in an overall fitness improvement of $\approx 25 \%$ over all output types normally used to assess fit.

Our discovery of the potential of GAs to derive improved parameter sets from high-level data will have profound implications on the speed at which we can develop locality-specific systems and on the accuracy of these systems to perform at that specific site. The GA was restricted to investigate parameter ranges that were within the realm of the field-observed variability. That is, parameters continued to maintain the original biological interpretations. We have demonstrated that we can develop a fine-tuned system that responds to local environments optimally given logical constraints on parameter ranges and functional forms.

GOSSYM is currently used throughout U.S. cotton-growing regions. A self-correcting feature was developed that allowed the model to rederive its parameters when field data indicated that forecasts were beyond an arbitrarily set threshold of acceptability. The process of finding the optimal configuration of parameter sets has been completely automated. The process of model correction thus depends only on the model's perceived goodness of fit. If it does not fit data well, it will invoke its associated GA and evolve a better set of parameters. This research implies that models may be applicable and have improved forecast efficacy over a wider range of conditions than is presently the case. This improvement in performance and applicability will affect natural resource management.

\section{CONCLUSIONS}

The level of detail used in a biological simulation model depends on its objectives and the accuracy or fidelity with which processes are simulated. Hierarchy theory states that if one is simulating at the whole-plant level, then details must be included at least two levels of abstraction down from the whole-plant level. It has been our experience that, as one increases the level of scientific mechanism in crop models, the system becomes more robust and less brittle. One must validate, validate, validate! Mechanisms that on the surface seem to be perfectly reasonable and plausible to put in a model may actually not function properly. The only way to find out is to integrate the mechanism, calibrate the model, and run validation tests. Verification tests at the component level do not always tell the story. New methodology is being developed to aid in model calibration. This new methodology uses GAs from the field of artificial intelligence. Our first efforts in this arena have given very promising results.

Literature Cited

Baker, D.N., J.R. Lambert, and J.M. McKinion. 1983. GOSSYM: A simulator of cotton growth and yield. South Carolina Agr. Expt. Sta. Tech. Bul. 1089.
Boone, M.Y.L.,D.O Porter, and J.M. McKinion. 1993. Calibration of GOSSYM: Theory and practice. Computers Electronics Agr. 9:193-203.

Curry, G.L. and R.M. Feldman. 1987. Mathematical foundations of population dynamics. Texas A\&M Univ. Press, College Station.

Davis, L. 1991. Handbook of genetic algorithms. Van Nostrand Reinhold, New York.

Fye, R.E., V.R. Reddy, and D.N. Baker. 1984. Validation of GOSSYM: Part I. Arizona conditions. Agr. Systems 14:85-105.

Goldberg, D.E. 1989. Genetic algorithms in search, optimization, and machine learning. Addison-Wesley, Reading, Mass.

Goldberg, D.E. and J. Richardson. 1987. Genetic algorithm with sharing for multimodal function optimization, p. 41-49. In: J.J. Grefenstette (ed.). Genetic algorithms and their applications. Proc. 2nd Intl. Conf. Genet. Algorithms. L. Erlebaum Assoc. Publishers, Hillsdale, N.J.

Holland, J.H. 1992. Adaptation in natural and artificial systems. MIT Press, Cambridge, Mass.

Liepins, G.E., M.R. Hilliard, M. Palmer, and M. Morrow. 1987. Greedy genetics, p. 90-99. In: J.J. Grefenstette (ed.). Genetic algorithms and their applications. Proc. 2nd Intl. Conf. Genet. Algorithms. L. Erlebaum Assoc. Publishers, Hillsdale, N.J.

McKinion, J.M. 1986. SPARNET: A data acquisition, analysis computer network. Computers Electronics Agr. 1:31-40.

McKinion, J.M. and D.N. Baker. 1982. Modeling experimentation, verification, and validation: Closing the feedback loop. Trans. Amer. Soc. Agr. Eng. 25(3):647-653.

McKinion, J.M., D.N. Baker, F.D. Whisler, and J.R. Lambert. 1989. Application of the GOSSYM/COMAX system to cotton crop management. Agr. Systems 31:55-65.

Parsons, J.E., J.L. Dunlap, J.M. McKinion, C.J. Phene, and D.N. Baker. 1980. Microprocessor-based data acquisition and control software for plant growth chambers (SPAR system). Trans. Amer. Soc. Agr. Eng. 23(3):589-595.

Phene, C.T., D.N. Baker, J.R. Lambert, and J.M. McKinion. 1978. SPAR-A soil-plant-atmosphere-research system. Trans. Amer. Soc. Agr. Eng. 21:924-930.

Reddy, K.R., H.F. Hodges, and J.M. McKinion. 1992. Cotton response to global climate change. World Resources Rev. 4(3):348-365.

Reddy, K.R., H.F. Hodges, and J.M. McKinion. 1993. A temperature model for cotton phenology. Biotronics 2:47-59.

Reddy, V.R., D.N. Baker, and J.N. Jenkins. 1985. Validation of GOSSYM: Part II. Mississippi conditions. Agr. Systems 17:133-154.

Schultz, D.G. and J.L. Melsa. 1967. State functions and linear control systems. McGraw-Hill, New York.

Sequeira, R.A., R. Olson, and J. McKinion. 1993. Self-correction of simulation models using genetic algorithms. Intl. Joint Conf. Artificial Intelligence (IJCAI'93), AI Applications in Natural Resources, Chambery, France. p. 77-87.

Shannon, R. 1976. Simulation: The art and the science. Prentice Hall, New York.

Swartzman, G.L. and S.P. Kaluzny. 1987. Ecological simulation. MacMillan, New York.

Vansteenkiste, G.C. and J.A. Spriet. 1982. Modelling ill-defined systems. In: F.E. Cellier (ed.). 1982. Progress in modelling and simulation. Academic, New York.

Whisler, F.D., B. Acock, D.N. Baker, R.E. Fye, H.F. Hodges, J.R. Lambert, H.E. Lemmon, J.M. McKinion, and V.R. Reddy. 1986. Crop simulation models in agronomic systems. Adv. Agron. 40:142-208.

\title{
Response of Crop Photosynthesis to Carbon Dioxide, Temperature, and Light: Experimentation and Modeling
}

\author{
V.R. Reddy, L.B. Pachepsky, and B. Acock \\ U.S. Department of Agriculture, Agricultural Research Service, Natural Resources Institute, Systems Research \\ Laboratory, Building 007, Room 008, Beltsville Agricultural Research Center-West, Beltsville, MD 20705
}

Interest in the response of crop photosynthesis to atmospheric $\mathrm{CO}_{2}$ concentration $\left(\left[\mathrm{CO}_{2}\right]\right)$, temperature, and light is growing in ecophysiological research and practical agriculture. Horticulturists are interested because greenhouses often have elevated $\mathrm{CO}_{2}$. Agronomists and ecologists have to take into account in their crop development and productivity predictions that ambient $\left[\mathrm{CO}_{2}\right]$ is increasing, which is expected to increase global air temperature.

The cost of publishing this paper was defrayed in part by the payment of page charges. Under postal regulations, this paper therefore must be hereby marked advertisement solely to indicate this fact.
Canopy photosynthesis models have been proposed, but a method to validate, compare, and choose the most suitable model for a particular application is needed. Such a method is presented here and is used to show that a hyperbolic model is adequate for describing the effects of light, $\left[\mathrm{CO}_{2}\right]$, and air temperature on canopy photosynthesis.

The hyperbolic model was fitted to experimental data on cotton (Gossypium hirsutum L.) canopy $\mathrm{CO}_{2}$ exchange obtained in daylit controlled-environment chambers in a range of $\left[\mathrm{CO}_{2}\right]$ and air temperatures. Canopy light-use efficiency depended on temperature, while canopy conductance to $\mathrm{CO}_{2}$ transfer was a function of air temperature and $\left[\mathrm{CO}_{2}\right]$. The complete model of cotton canopy photosynthesis 
contains seven parameters that can be determined from canopy $\mathrm{CO}_{2}-$ exchange data. Methods and results of photosynthesis model parameterization with data on canopy and leaf $\mathrm{CO}_{2}$ exchange are also compared.

Photosynthetic light response curves have been studied for various plant species during the last several decades. Carbon dioxide and temperature dependencies of canopy $\mathrm{CO}_{2}$ exchange have become the object of intensive study only during the last 15 years. Carbon dioxide response curves were developed as a result of research into photosynthesis mechanisms (Laisk, 1977) and they have been used in greenhouse horticulture for optimizing $\left[\mathrm{CO}_{2}\right]$ control. Recently, this area of research has become the center of interest for a wide circle of researchers. Increasing atmospheric $\mathrm{CO}_{2}$ is expected to result in a $\left[\mathrm{CO}_{2}\right]$ of $600 \mu \mathrm{l} \cdot \mathrm{liter}^{-1}$ by about the middle of the 21 st century. This increase will likely affect global climate primarily by increasing air temperature 3 to $6 \mathrm{C}$ (Wetherald, 1989). Data on light, $\left[\mathrm{CO}_{2}\right]$, and temperature response of photosynthesis are also necessary for assessing the use of crops for human life-support in closed habitats envisioned for space. Results of such measurements can be used to model the use of plants to remove $\mathrm{CO}_{2}$, produce $\mathrm{O}_{2}$, and evaporate water for controlled ecological life-support systems (Wheeler et al., 1993).

The increasing need to predict crop growth at elevated $\left[\mathrm{CO}_{2}\right]$ and temperature has made simulation models essential tools for integrating information across levels of organization and for making quantitative predictions. Five approaches for predicting canopy assimilation using a submodel of leaf photosynthesis are described by Boote and Loomis (1991). The first and simplest approach is to multiply leaf photosynthesis by leaf area index (LAI), which is correct only for LAIs <1.0. This method overestimates canopy photosynthesis at higher LAIs and high light flux densities. The second approach is the big-leaf approach, in which the plant canopy is treated as a single leaf. It often underestimates canopy assimilation. A third approach, proposed by Sinclair (1991), is based on two leaf classes: those exposed to direct solar radiation and those that are shaded. A fourth approach, proposed by Denison and Loomis (1989), includes numerical integration through several leaf layers. This method is very complex, but the prediction can be excellent.

A fifth approach, proposed by Acock et al. (1978), uses a hyperbolic analytical description of photosynthesis and the variation in leaf photosynthetic characteristics with canopy depth. In this approach, canopy properties are accounted for by three parameters that depend on environmental factors.

Many models have been developed to describe leaf photosynthesis. Parameters of these models are usually determined from experimental data (Acock, 1991; Evans and Farquhar, 1991). However, validating models with experimental data is still not a common procedure. Model adequacy is sometimes estimated by visually comparing calculated and measured data, but the model usually is not analyzed quantitatively over the entire range of conditions. Methods for analyzing models quantitatively were developed long ago and have been used successfully, for instance, in chemical technology (Himmelblau, 1968).

The essential difference between laboratory and field data is that the latter are more variable as a result of environmental variability. The data obtained from daylit controlled-environment chambers are affected by variable light, as in the field, but they are measured at stable, controlled values of $\left[\mathrm{CO}_{2}\right]$ and air temperature. Such data are more reliable then field data for parameterizing a photosynthesis model developed to predict plant responses to elevated $\left[\mathrm{CO}_{2}\right]$ and temperature.

This study presents 1 ) the results of cotton and tomato (Lycopersicon esculentum Mill.) $\mathrm{CO}_{2}$-exchange measurements in a wide range of $\left[\mathrm{CO}_{2}\right]$ at various air temperatures, 2) the validation of a canopy photosynthesis model and comparison with a leaf photosynthesis model, and 3) the analysis of dependencies of the main model parameters on $\left[\mathrm{CO}_{2}\right]$ and temperature compared with the same parameters for a single leaf.

\section{TEST PROCEDURES}

General. 'DPL 50' cotton seeds were sown on wet filter paper at 28/ $23 \mathrm{C}$ (day/night). Germinating seeds were selected for uniformity and planted in naturally irradiated controlled-environment plant growth chambers in 11 rows with five plants per row on 15 May 1989 near Starkville, Miss. (lat. $30.5^{\circ} \mathrm{N}$ ). Row length was $0.5 \mathrm{~m}$ and row width was $0.18 \mathrm{~m}$. The initial plant population was 55 plants $/ \mathrm{m}^{2}$. The chambers consisted of a steel bin containing the rooting medium and measuring $1.0 \mathrm{~m}$ high $\times 2.0 \mathrm{~m}$ long $\times 0.5 \mathrm{~m}$ wide. An acrylic base on top of this soil bin held the aerial parts of the plants and measured 2.0 $\mathrm{m}$ high $\times 2.0 \mathrm{~m}$ long $\times 1.5 \mathrm{~m}$ wide. The growing medium was a mixture of 3 sand : 1 vermiculite $(\mathrm{v} / \mathrm{v})$, with slow-release micronutrients added at $88 \mathrm{mg} \cdot$ liter $^{-1}$ before the soil bins were filled. Six plant rows were harvested 23 days after emergence (DAE) and two more rows were harvested $35 \mathrm{DAE}$ to reduce light competition. At final harvest, there were three rows that corresponded to 15 plants $/ \mathrm{m}^{2}$. Air in the chambers was maintained at 28/23C (day/night) during seedling emergence and until 14 DAE. At $15 \mathrm{DAE}$, various temperatures and $\left[\mathrm{CO}_{2}\right]$ treatments were imposed.

Temperature and $\left[\mathrm{CO}_{2}\right]$. In Expt. 1, air in 10 growth chambers was maintained at 15/7, 20/12, 25/17, 30/22, and 35/27C (day/night). Carbon dioxide was maintained at 350 or $700 \mu \mathrm{l} \cdot \mathrm{liter}^{-1}$ at each temperature level. Day temperature was initiated $1 \mathrm{~h}$ after sunrise and night temperature was initiated $1 \mathrm{~h}$ after sunset. In Expt. 2, $\left[\mathrm{CO}_{2}\right]$ was maintained in five chambers at $350,450,600,750$, or $900 \mu 1 \cdot$ liter $^{-1}$. The day/night temperature of the chambers was maintained at 30/18C. Air temperature, $\left[\mathrm{CO}_{2}\right]$, and irrigation in the chambers were computer controlled and monitored. Graded shadecloths were hung around the chamber sides up to plant height to simulate the decreased light intensity normally caused by adjacent plants in field conditions. Baffles were installed in the chambers for air mixing, and continuous air circulation controlled the temperature uniformly throughout the chamber. The chambers were sealed, and $\left[\mathrm{CO}_{2}\right]$ of the air was monitored at 10 -sec intervals and averaged for each 900 -sec period. Carbon dioxide content of the air in each chamber was monitored with a dedicated conductimetric analyzer. The conductimetric analyzers were checked with an infrared gas analyzer for calibration every 15 min, after which a computer adjusted the calibration curves when necessary. To maintain $\left[\mathrm{CO}_{2}\right]$ in the chambers, pure $\mathrm{CO}_{2}$ was injected through a solenoid valve and a calibrated flowmeter. Each flowmeter was calibrated with a gas-displacement meter (Brooks; Emerson Electric Co., Hatfield, Pa.) at the beginning and end of each experiment. Carbon dioxide flow rates were recorded three times per day. Each night, the leakage rate of each chamber was determined using the procedure described by Acock and Acock (1989). Canopy interception of solar radiation was measured with a radiation sensor (model LI1915B; LI-COR, Lincoln, Neb.) 63 DAE for the various day/night temperatures and 83 to $102 \mathrm{DAE}$ for the $\left[\mathrm{CO}_{2}\right]$ noted. The amount of $\mathrm{CO}_{2}$ injected, air chamber volume, atmospheric pressure, chamber temperature, and chamber leakage rate were used to calculate plant photosynthesis during the day and respiratory rates during the night over each 15-min interval.

Model comparison. To compare a canopy photosynthesis model with a single-leaf photosynthesis model, data from a laboratory experiment by Stanghellini and Bunce (1993) have been analyzed. In this experiment, 'Rutgers Large Red' tomato $\mathrm{CO}_{2}$-exchange rates for single attached leaves were determined by gas-exchange techniques at three leaf temperatures as functions of short-term variation in $\left[\mathrm{CO}_{2}\right]$ and light. The experiments were conducted on fully expanded leaves of plants grown in vermiculite-filled pots, flushed daily with a nutrient solution, at $\left[\mathrm{CO}_{2}\right]$ of either 350 or $700 \mu l \cdot$ liter $^{-1}$. The conditions during growth were air temperature $25 \mathrm{C}$, relative humidity $70 \%$, photosynthetic photon density $500 \mu \mathrm{mol} \cdot \mathrm{m}^{-2} \cdot \mathrm{s}^{-1}$, and photoperiod $14 \mathrm{~h}$.

At the beginning of each measurement (27 to 31 days after sowing), a side leaflet (of either the fourth or the fifth leaf) was enclosed in a gasexchange chamber in which $\left[\mathrm{CO}_{2}\right]$, light, air temperature, and humidity could be manipulated continuously. Carbon dioxide exchange rates were measured at four $\left[\mathrm{CO}_{2}\right]$ of the incoming air-100, 350, 700, and $1000 \mu \mathrm{l} \cdot$ liter $^{-1}$. Light was supplied by incandescent lamps through a water filter at fluxes of 50,100, 150, 500, 800, 1100, 1400, 1700, and $2000 \mu \mathrm{mol} \cdot \mathrm{m}^{-2} \cdot \mathrm{s}^{-1}$. Measurements were taken at three temperatures $(18,25$, and 32C).

Data analysis. Gross canopy $\mathrm{CO}_{2}$ exchange rate of cotton vs. irradiance was fitted to Model [1]: 
where $P$ is gross canopy $\mathrm{CO}_{2}$ exchange rate $\left(\mathrm{mg} \cdot \mathrm{m}^{-2} \cdot \mathrm{s}^{-1}\right) ; I$ is the light flux density incident on the canopy $\left(\mathrm{W} \cdot \mathrm{m}^{-2}\right) ; C$ is $\left[\mathrm{CO}_{2}\right]$ in the air $\left(\mathrm{mg} \cdot \mathrm{m}^{-3}\right) ; \alpha_{c}$ is canopy light-use efficiency $\left(\mathrm{mg} \mathrm{CO}_{2} / \mathrm{W}\right) ; \tau_{c}$ is canopy conductance to $\mathrm{CO}_{2}$ transfer $\left(\mathrm{m} \cdot \mathrm{s}^{-1}\right)$; and $\beta$ is a matching term $\left(\mathrm{mg} \cdot \mathrm{m}^{-2} \cdot \mathrm{s}^{-1}\right)$. Gross canopy $\mathrm{CO}_{2}$ exchange rate was calculated by adding the dark respiration rate measured at the daytime temperature during the first hour of the night to all net photosynthesis rate values for the previous day. Since $P$ is gross canopy $\mathrm{CO}_{2}$-exchange rate, $\beta$ is not dark respiration; it can be considered as a term introduced to increase the accuracy of the model by adjusting for photorespiration.

Single-leaf, $\mathrm{CO}_{2}$-exchange rate of tomato vs. irradiance was fitted to a three-parameter model of the same kind as Model [1]:

Model [2]

and to Farquhar's model (Evans and Farquhar, 1991)

Model [3]
In Models [2] and [3], $P_{1}$ is photosynthesis ( $\mu \mathrm{mol} \mathrm{CO} / \mathrm{m}^{2}$ per sec), $R$ is respiration ( $\mu \mathrm{mol} \mathrm{CO} \mathrm{CO}_{2} / \mathrm{m}^{2}$ per sec), $I$ is light flux density at the leaf surface ( $\mu \mathrm{mol}$ photons $/ \mathrm{m}^{2}$ per sec), $C$ is $\left[\mathrm{CO}_{2}\right]$ in air $\left(\mu \mathrm{mol} \cdot \mathrm{m}^{-3}\right), \alpha$ is leaf light-use efficiency ( $\mu \mathrm{mol} \mathrm{CO} / / \mu \mathrm{mol}$ photons), $\tau$ is leaf conductance to $\mathrm{CO}_{2}$ transfer $\left(\mathrm{m} \cdot \mathrm{s}^{-1}\right)$, and $\theta$ is a dimensionless curvature factor $(0 \leq \theta \leq 1)$. Model 3 has four parameters: $\alpha, \tau, R$, and $\theta$.

Cotton canopy light response curves for every combination of $\left[\mathrm{CO}_{2}\right]$ and temperature were fitted with Model [1] and tomato leaf light response curves for all $\mathrm{CO}_{2}$ and temperature treatments were fitted with Models [2] and [3]. For all models, a modified Marquardt algorithm (Marquardt, 1963; Pachepsky et al., 1982) has been used for fitting. This method allows the calculation of the parameter values and their statistical characteristics, i.e., SDS, confidence intervals, residuals, correlation coefficients of residuals, and Student's criteria.

The values of $\alpha_{c}, \tau_{c}$, and $\beta$ and $\alpha, \tau, R$, and $\theta$ were calculated for every treatment, and the dependencies of these parameters on environmental factors were analyzed. The adequacy of the model was assessed by $\mathrm{F}$ test, analysis of residuals, and autocorrelation coefficient $(\kappa)$ test (Haflon, 1985; Himmelblau, 1968).

Model adequacy. All of the data, regardless of their scatter, were successfully fitted by Model [1]. Results for six combinations of $\left[\mathrm{CO}_{2}\right]$ and temperature show that the scatter in the photosynthesis data was significantly higher at the lower day/night temperatures-15/7C (Fig.
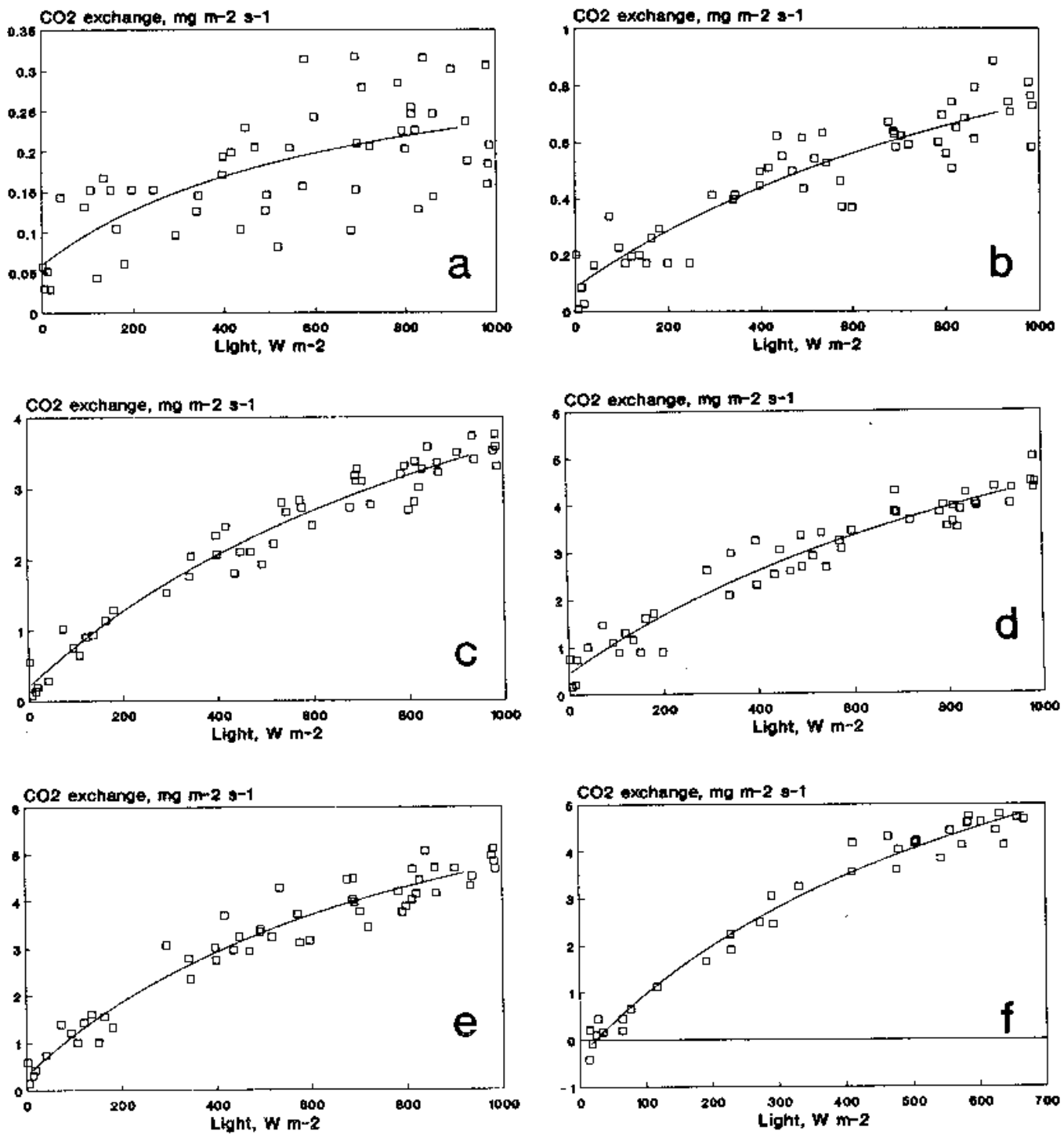

Fig. 1. Photosynthesis light response curves for a cotton canopy 63 days after emergence (DAE) at $\left[\mathrm{CO}_{2}\right]$ of $350 \mu 1 \cdot$ liter ${ }^{-1}$ and at various day/night temperatures ( ${ }^{\circ} \mathrm{C}$ ): (a) 15/7, (b) 20/12, (c) 25/17, (d) 30/22, (e) 35/27, and (f) $93 \mathrm{DAE}, 30 / 18 \mathrm{C}$, and $\left[\mathrm{CO}_{2}\right]$ at $900 \mu 1 \cdot \mathrm{liter}^{-1}$. Measured points and fitted curves are shown. 
1a) and 20/12C (Fig. 1b). The substantial scatter was caused by the smaller signal : noise ratio than at higher temperatures. Parameters for all 15 photosynthetic light response curves are shown in Table 1.

Model 1 was adequate quantitatively according to the $F$ test for all combinations of environmental factors (Table 2). The model's qualitative adequacy was tested by the analysis of residuals, which were randomly distributed with respect to light (Fig. 2). Values of $\kappa$ were less than $\kappa_{c r}$ in 13 cases, and only in two cases (Table 2) were the $\kappa$ values higher than the critical values of 0.339 and 0.288 , respectively, at $P \leq 0.05$ (Gomez and Gomez, 1983).

The three-parameter hyperbolic Model [1] for modeling $\mathrm{CO}_{2}$ exchange in a cotton canopy is therefore adequate for describing data obtained in daylit controlled-environment chambers. Including additional parameters in the model cannot improve model quality because of the scatter in the data.

For the data on tomato leaf $\mathrm{CO}_{2}$ exchange obtained in a leaf chamber with much lower scatter, the more complicated four-parameter Farquhar's Model [3] was better than the three-parameter Model [2]. The hyperbolic Model [2] was not adequate qualitatively for all treatments of the tomato leaf experiment.

Light response curves. The cotton canopy $\mathrm{CO}_{2}$-exchange rate at light saturation, $P_{s}\left(P_{s}=\tau_{c} C\right)$, varied from $0.293 \mathrm{mg} \cdot \mathrm{m}^{-2} \cdot \mathrm{s}^{-1}$ at $15 / 7 \mathrm{C}$ and $\left[\mathrm{CO}_{2}\right]$ at $350 \mu \mathrm{l} \cdot \mathrm{liter}^{-1}$ to $12.810 \mathrm{mg} \cdot \mathrm{m}^{-2} \cdot \mathrm{s}^{-1}$ at $35 / 27 \mathrm{C}$ and $\left[\mathrm{CO}_{2}\right]$ at $700 \mu \mathrm{l} \cdot \mathrm{liter}^{-1}$ (Table 1 ). Light saturation was actually reached in only 4 of the 15 treatments, at $15 / 7$ and $20 / 12 \mathrm{C}$ for $\left[\mathrm{CO}_{2}\right]$ at 350 and $700 \mu \mathrm{l} \cdot$ liter $^{-1}$.

Figure 3 shows light response curves $30 / 18 \mathrm{C}$ and five $\left[\mathrm{CO}_{2}\right]$ values. The higher $\left[\mathrm{CO}_{2}\right]$ gave higher $\mathrm{CO}_{2}$-exchange rates when irradiance exceeded $200 \mathrm{~W} \cdot \mathrm{m}^{-2}$. Light-saturated photosynthesis was not reached for these treatments, but the light response curves show that the maximal $\mathrm{CO}_{2}$-exchange rate depends on $\left[\mathrm{CO}_{2}\right]$. The nonlinear dependence of $\mathrm{CO}_{2}$-exchange rate on temperature (Figs. 4 and 5) is evident at 350 and $700 \mu l \cdot l i t e r^{-1}$. At both $\left[\mathrm{CO}_{2}\right]$, the saturated $\mathrm{CO}_{2}$-exchange rate was higher at higher temperatures. Analogous results have been published for soybeans [Glycine $\max$ (L.) Merr.] (Acock et al., 1985).

The dependencies we observed for cotton are not necessarily valid for other species. Studies for a single leaf show that various species react to elevated $\mathrm{CO}_{2}$ in different ways. Sage et al. (1989) studied the effect of $\mathrm{CO}_{2}$ enrichment on gas-exchange characteristics and found that there were different reaction patterns to elevated $\left[\mathrm{CO}_{2}\right]$. For some species (Solanum tuberosum L.), the initial slope of the $\mathrm{CO}_{2}$ response curve was unaffected, but the photosynthetic rate increased with increasing $\left[\mathrm{CO}_{2}\right]$, as observed in this cotton study. For other species (Chenopodium album L., Phaseolus vulgaris L.), with increasing $\left[\mathrm{CO}_{2}\right]$, the initial slope decreased and the $\mathrm{CO}_{2}$-saturated photosynthesis rate was affected very little. For Brassica oleracea $\mathrm{L}$. and $S$. melongena $\mathrm{L}$., the initial slopes and the $\mathrm{CO}_{2}$-saturated rate decreased with increasing $\left[\mathrm{CO}_{2}\right]$. We can compare the parameters $\alpha$ and $\tau$ for these species, considering $\mathrm{CO}_{2}$ and light response curves as hyperbolic functions. Analyzing these parameters calculated from the data in Sage et al. (1989) reveals that these parameters vary in different ways, depending on species. Light-use efficiency, $\alpha$, grew after acclimation for $S$. tuberosum and C. album; $\alpha$ was not affected by higher $\left[\mathrm{CO}_{2}\right]$ for $P$. vulgaris and it was significantly lower for acclimated $B$. oleracea plants. Conductance, $\tau$, did not change during acclimation for $S$. tuberosum, but it was lower for high $\left[\mathrm{CO}_{2}\right]$-acclimated C. album, $P$. vulgaris, and B. oleracea plants.

Sage et al. (1989) emphasized that no two species exhibited identical quantitative responses to $\mathrm{CO}_{2}$ enrichment and that no species exhibited an idealized acclimation response at the biochemical level. At the same time, the acclimation to high $\mathrm{CO}_{2}$ develops first at the biochemical level and appears to be complicated and controversial. Various explanations are possible for the effect of long-term high $\left[\mathrm{CO}_{2}\right]$ on photosynthesis. The different character of S. tuberosum reactions on one hand and of the other considered species on the other hand can be explained at the level of source-sink relationships. A

Table 1. Parameter values of Model [1] for cotton for various combinations of environmental conditions.

\begin{tabular}{|c|c|c|c|c|c|c|}
\hline Treatment & $\begin{array}{c}{\left[\mathrm{CO}_{2}\right]} \\
\left(\mu \mathrm{l} \cdot \text { liter }^{-1}\right)\end{array}$ & $\begin{array}{c}\text { Temp }\left({ }^{\circ} \mathrm{C}\right) \\
\text { day/night }\end{array}$ & $\begin{array}{c}\alpha_{c} \\
\left(\mathrm{mg} \cdot \mathrm{W}^{-1}\right)\end{array}$ & $\begin{array}{c}\tau_{c} C \\
\left(\mathrm{mg} \cdot \mathrm{m}^{-2} \cdot \mathrm{s}^{-1}\right)\end{array}$ & $\begin{array}{c}\tau_{c} 10^{3} \\
\left(\mathrm{~m} \cdot \mathrm{s}^{-1}\right)\end{array}$ & $\begin{array}{c}\beta \\
\left(\mathrm{mg} \cdot \mathrm{m}^{-2} \cdot \mathrm{s}^{-1}\right)\end{array}$ \\
\hline 1 & 350 & $30 / 18$ & 0.00915 & 8.156 & 10.022 & 0.290 \\
\hline 2 & 450 & $30 / 18$ & 0.01057 & 9.179 & 15.776 & 0.308 \\
\hline 3 & 600 & $30 / 18$ & 0.01110 & 12.260 & 15.803 & -0.038 \\
\hline 4 & 750 & $30 / 18$ & 0.01290 & 10.120 & 10.436 & -0.224 \\
\hline 5 & 900 & $30 / 18$ & 0.01485 & 10.670 & 9.169 & -0.334 \\
\hline 6 & 350 & $15 / 7$ & 0.00044 & 0.293 & 0.647 & 0.060 \\
\hline 7 & 350 & $20 / 12$ & 0.00115 & 1.498 & 3.310 & 0.088 \\
\hline 8 & 350 & $25 / 17$ & 0.00615 & 7.501 & 16.575 & 0.214 \\
\hline 9 & 350 & $30 / 22$ & 0.00694 & 9.414 & 20.802 & 0.452 \\
\hline 10 & 350 & $35 / 27$ & 0.00944 & 8.404 & 18.570 & 0.318 \\
\hline 11 & 700 & $15 / 7$ & 0.00267 & 0.465 & 0.514 & -0.153 \\
\hline 12 & 700 & $20 / 12$ & 0.00329 & 0.785 & 0.868 & 0.053 \\
\hline 13 & 700 & $25 / 17$ & 0.00754 & 9.037 & 9.985 & 0.166 \\
\hline 14 & 700 & $30 / 22$ & 0.01180 & 10.630 & 11.745 & 0.342 \\
\hline 15 & 700 & $35 / 27$ & 0.01183 & 12.810 & 14.153 & 0.205 \\
\hline
\end{tabular}

Table 2. Results of Model [1] for cotton validation by $\mathrm{F}$ test $\left(\mathrm{F}<\mathrm{F}_{k-p, N-k}\right)$ and autocorrelation coefficient test $\left(\kappa<\kappa_{c r}\right)$.

\begin{tabular}{|c|c|c|c|c|c|c|}
\hline Treatment & $\begin{array}{c}{\left[\mathrm{CO}_{2}\right]} \\
\left(\mu 1 \cdot \cdot \text { liter-1 }^{-1}\right) \\
\end{array}$ & $\begin{array}{c}\text { Temp }\left({ }^{\circ} \mathrm{C}\right) \\
\text { day/night }\end{array}$ & $\mathrm{F}_{k-p, N-k}$ & $\mathrm{~F}$ & $\kappa_{c r}$ & $|\kappa|$ \\
\hline 1 & 350 & $30 / 18$ & 2.98 & 1.79 & 0.339 & 0.368 \\
\hline 2 & 450 & $30 / 18$ & 2.84 & 1.18 & 0.329 & 0.021 \\
\hline 3 & 600 & $30 / 18$ & 2.93 & 0.59 & 0.329 & 0.259 \\
\hline 4 & 750 & $30 / 18$ & 2.17 & 0.64 & 0.339 & 0.188 \\
\hline 5 & 900 & $30 / 18$ & 3.07 & 1.15 & 0.329 & 0.079 \\
\hline 6 & 350 & $15 / 7$ & 2.47 & 2.33 & 0.273 & 0.268 \\
\hline 7 & 350 & $20 / 12$ & 2.47 & 0.84 & 0.260 & 0.211 \\
\hline 8 & 350 & $25 / 17$ & 2.47 & 0.96 & 0.273 & 0.114 \\
\hline 9 & 350 & $30 / 22$ & 2.63 & 1.12 & 0.273 & 0.079 \\
\hline 10 & 350 & $35 / 27$ & 2.63 & 1.17 & 0.273 & 0.007 \\
\hline 11 & 700 & $15 / 7$ & 2.54 & 1.98 & 0.288 & 0.387 \\
\hline 12 & 700 & $20 / 12$ & 2.63 & 1.38 & 0.273 & 0.097 \\
\hline 13 & 700 & $25 / 17$ & 2.63 & 1.17 & 0.273 & 0.256 \\
\hline 14 & 700 & $30 / 22$ & 2.63 & 1.58 & 0.273 & 0.073 \\
\hline 15 & 700 & $35 / 27$ & 2.54 & 1.12 & 0.273 & 0.148 \\
\hline
\end{tabular}


Residuals, mg m-2 s-1

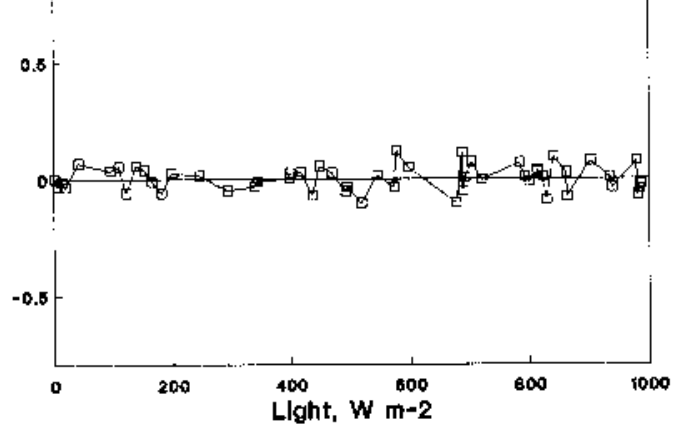

Regiduals, ma m-2 g-1

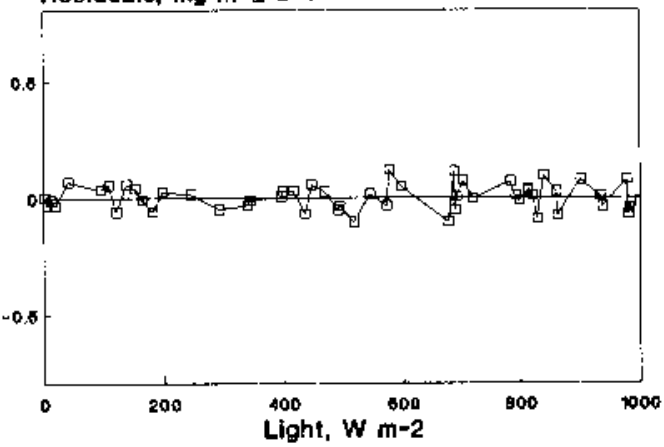

$25 / 17$ G, $350 \mathrm{~mL} L-1[\mathrm{CO} 2]$

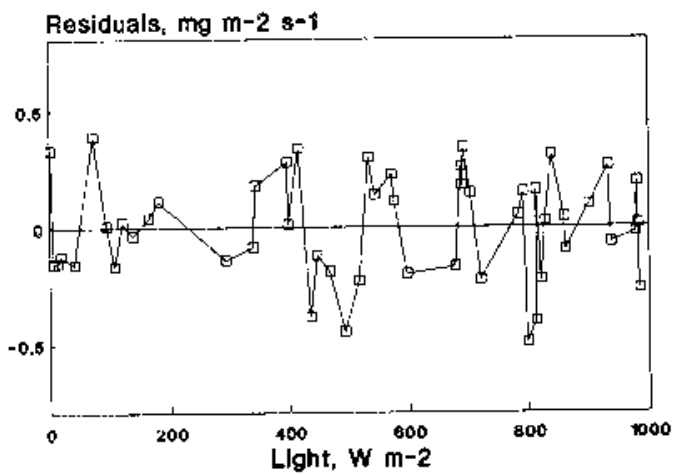

$30 / 22 \mathrm{C}, 360 \mathrm{mLL} /-1$ [CO2]

Residuals, $\mathrm{mg} \mathrm{m-2} \mathrm{s}-1$

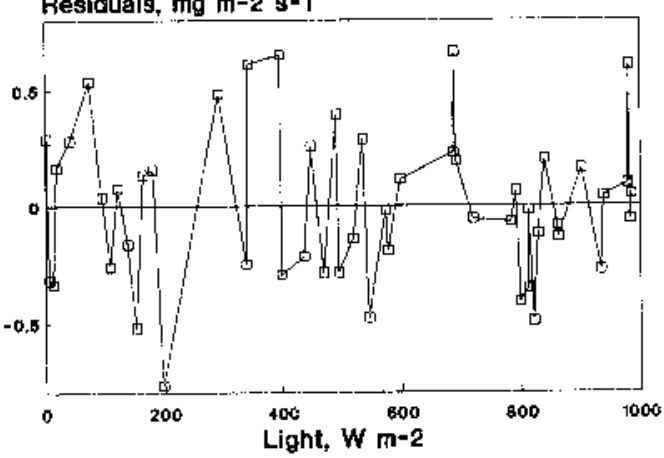

35/27 C. 350 mLL L-1 [CO2]

Residuals, $m g m-2 \mathrm{~g}-1$

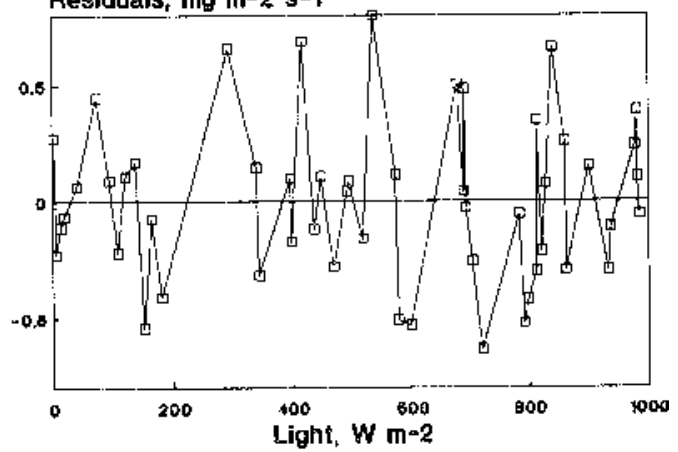

Fig. 2. Residuals for Model [1] at $\left[\mathrm{CO}_{2}\right]$ of $350 \mu l \cdot l i t e r^{-1}$.

higher demand for carbohydrates from an S. tuberosum tuber can facilitate acclimation by unloading extra starch from the chloroplast. The other species do not have such a sink for carbohydrates, and their acclimation can develop over a longer period than the duration of the experiment. Cotton plants in the current study positively affected by high $\mathrm{CO}_{2}$ have several assimilate sinks that can also positively affect cotton acclimation to elevated $\mathrm{CO}_{2}$.

Model 1 parameters. Cotton canopy light-use efficiency, $\alpha_{c}$, the initial slope of the canopy light response curve, varied from 0.00044 to $0.01485 \mathrm{mg} \cdot \mathrm{W}^{-1}$ (Table 1 ). The $\alpha_{c}$ at a given $\left[\mathrm{CO}_{2}\right]$ depended significantly on temperature (Fig. 6a). Linear regression of $\alpha_{c}$ on temperature provided the best fit with a correlation coefficient of 0.625. A similar relationship has been reported by Reddy et al. (1991). There were no statistically significant differences between $\alpha_{c}$ values for different $\left[\mathrm{CO}_{2}\right]$ at a constant temperature (Table 1), although $\alpha_{c}$ values were usually higher for higher $\left[\mathrm{CO}_{2}\right]$ at the same temperature.

Parameter $\beta$ did not depend on $\left[\mathrm{CO}_{2}\right]$, but the linear regression on temperature had a correlation coefficient of 0.714 (Fig. 6b). The canopy conductance to $\mathrm{CO}_{2}$ transfer, $\tau_{c}$, was strongly affected by temperature and $\left[\mathrm{CO}_{2}\right]$ (Table 1). The dependence on temperature was nonlinear (Fig. 7a), and the best fit to the data was obtained with Model [4] (Fig. 8a):

Model [4]

The same model was tested for tomato leaf conductance to $\mathrm{CO}_{2}$ transfer (Fig. 8b). This model gave a better fit to the tomato leaf data because the data were much less scattered than for the cotton canopy. The dependence of leaf and canopy conductance to $\mathrm{CO}_{2}$ transfer on $\left[\mathrm{CO}_{2}\right]$ and temperature has been shown in other studies (Boote and Loomis, 1991; Jarvis and Morison, 1981; Mansfield et al., 1981).

Ball et al. (1987) used much existing data on leaf conductance and developed an empirical model. They observed linear relationships between stomatal conductance and assimilation rate, relative humidity, and $\left[\mathrm{CO}_{2}\right]$. According to Ball's model, conductance declines with increasing $\left[\mathrm{CO}_{2}\right]$. Values of single-leaf stomatal conductance for 


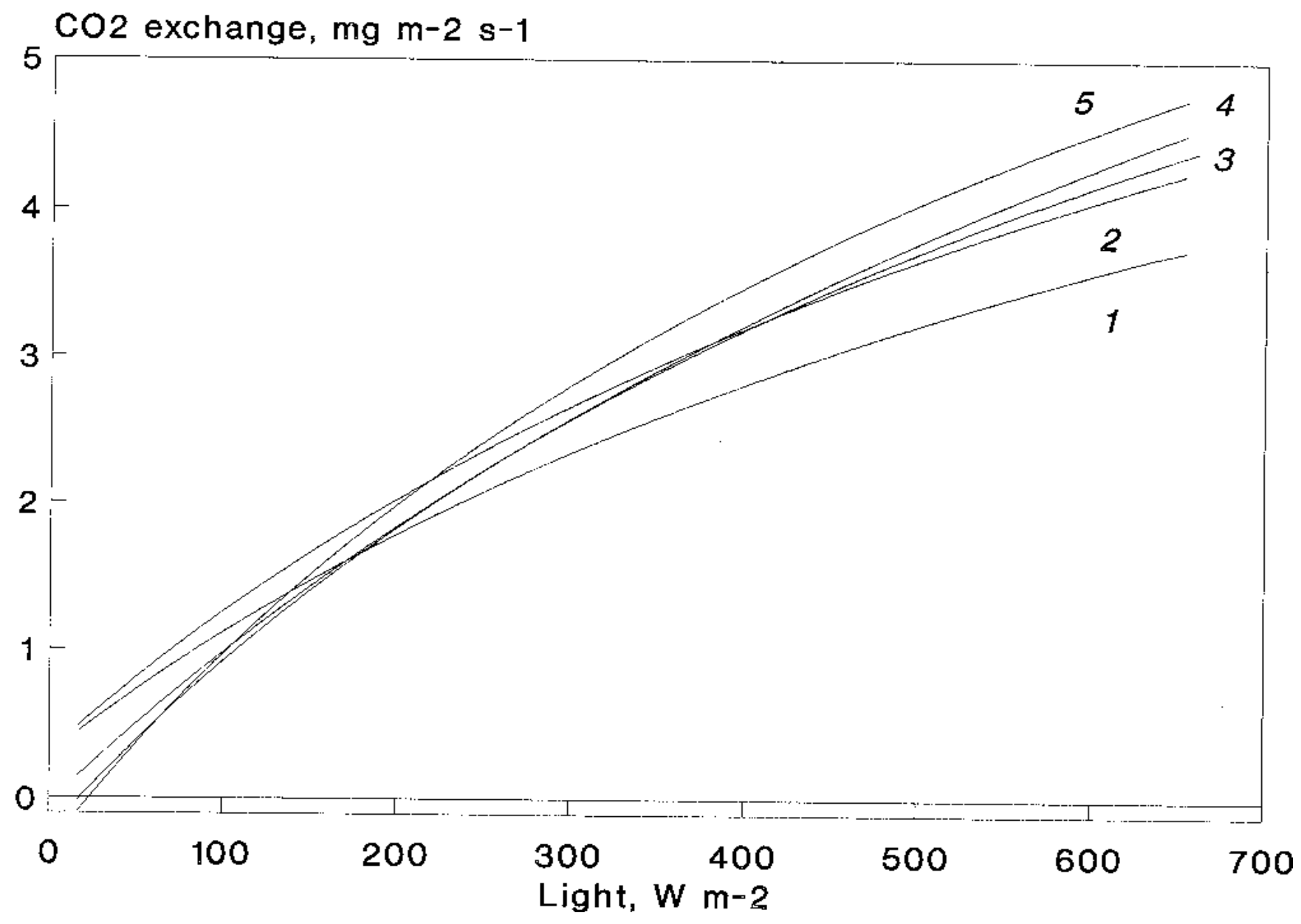

Fig. 3. Fitted photosynthesis light response curves for a cotton canopy 93 days after emergence, 30/18C, and various $\left[\mathrm{CO}_{2}\right]\left(\mu 1 \cdot 1\right.$ iter $\left.\left.\left.\left.{ }^{-1}\right): 1\right) 350,2\right) 450,3\right) 600$, 4) 750,5$) 900$.

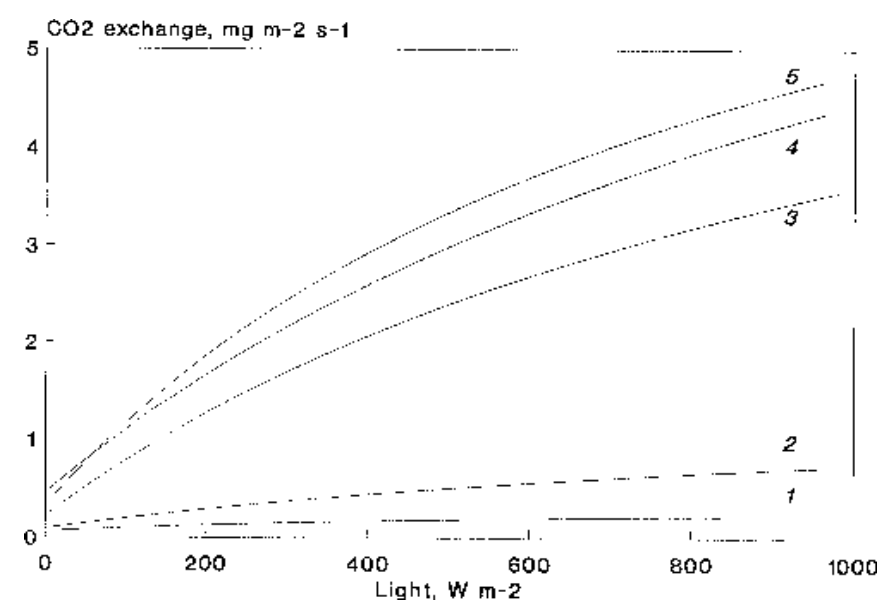

Fig. 4. Fitted photosynthesis light response curves for a cotton canopy 63 days after emergence at $\left[\mathrm{CO}_{2}\right] 350 \mu \mathrm{l} \cdot$ liter ${ }^{-1}$, and various day/night temperatures $\left({ }^{\circ} \mathrm{C}\right):$ 1) $15 / 7,2$ ) 20/12, 3) $25 / 17$, 4) 30/22, 5) 35/27.

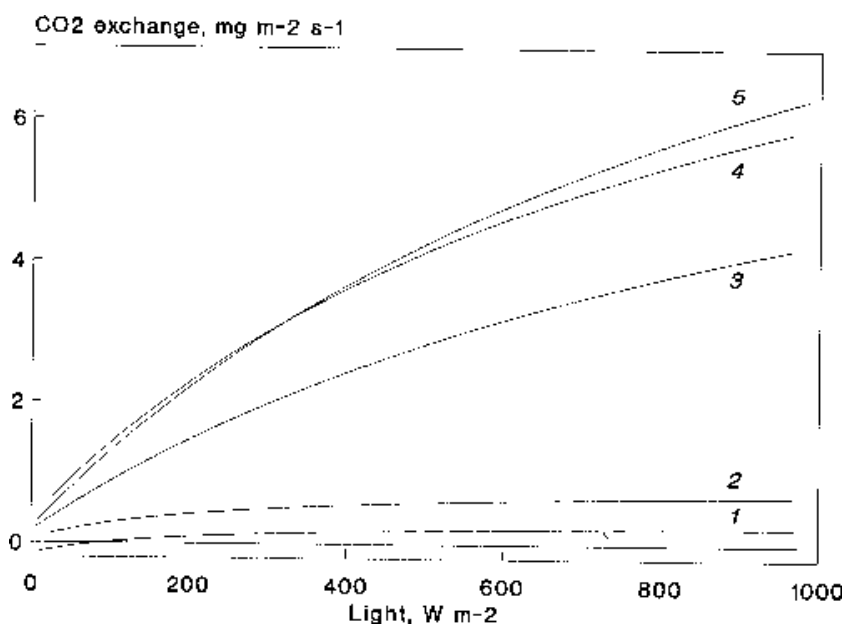

Fig. 5. Fitted photosynthesis light response curves for a cotton canopy 63 days after emergence at $\left[\mathrm{CO}_{2}\right] 700 \mu 1 \cdot 1$ iter ${ }^{-1}$, and various day/night temperatures $\left({ }^{\circ} \mathrm{C}\right):$ 1) $15 / 7,2$ ) 20/12, 3) $25 / 17$, 4) 30/22, 5) 35/27. 

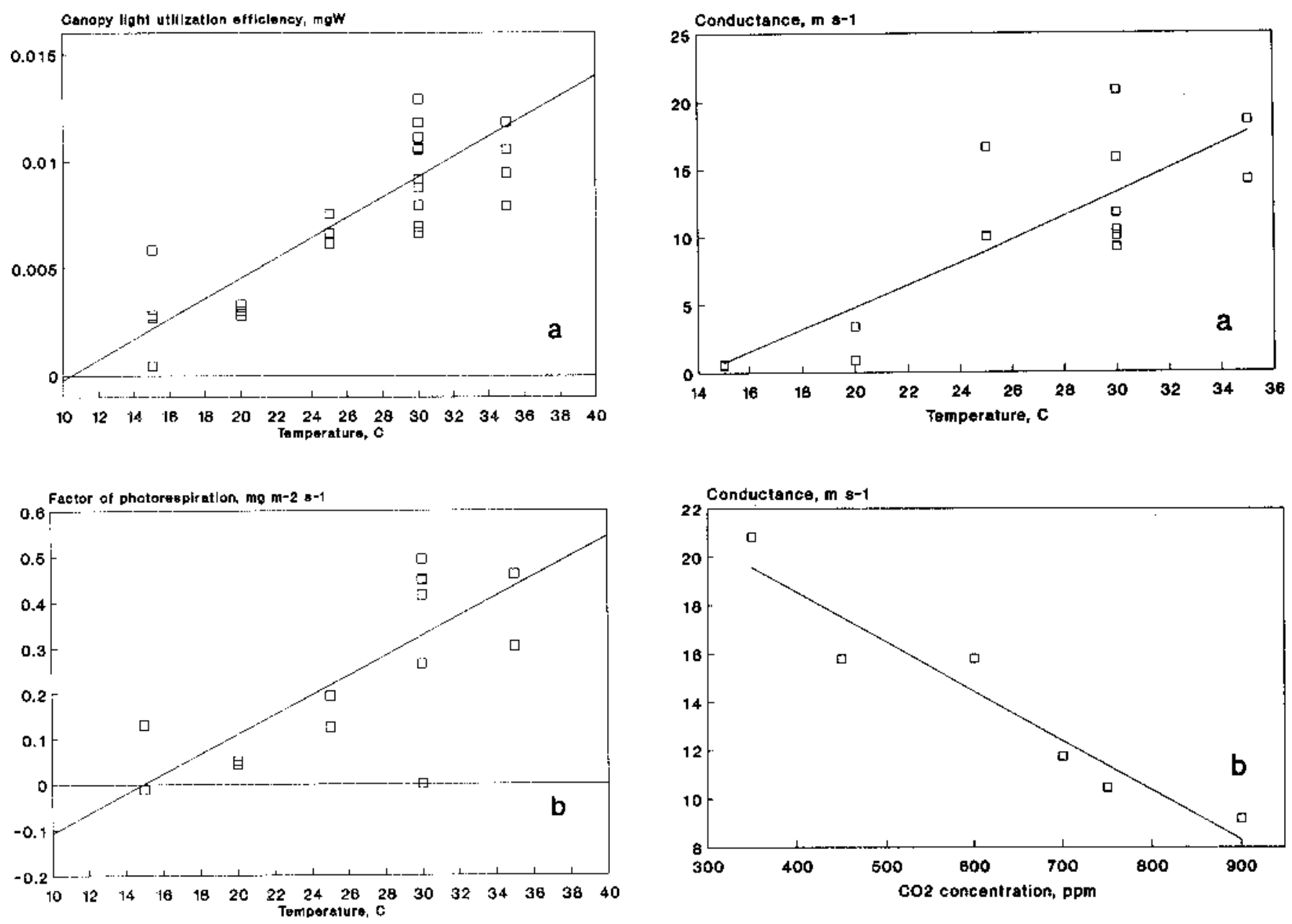

Fig. 6. Dependencies of (a) cotton canopy light-use efficiency $(\alpha=0.479 \cdot T E M P$ $5.11) \cdot 10^{-3}, r=0.625$, and $(\mathbf{b})$ matching factor $(\beta=0.022 \cdot T E M P-0.325, r=$ 0.714 ) on temperature.

Fig. 7. Dependencies of cotton canopy conductance on (a) temperature $(\tau=$ $95.48 \cdot \exp (0.0074 \cdot \boldsymbol{T E M P})-10.59, r=0.82$, and $(\mathbf{b}) \mathrm{CO}_{2}$ concentration $(\tau=-0.0205 \cdot C+26.75, r=0.95)$.
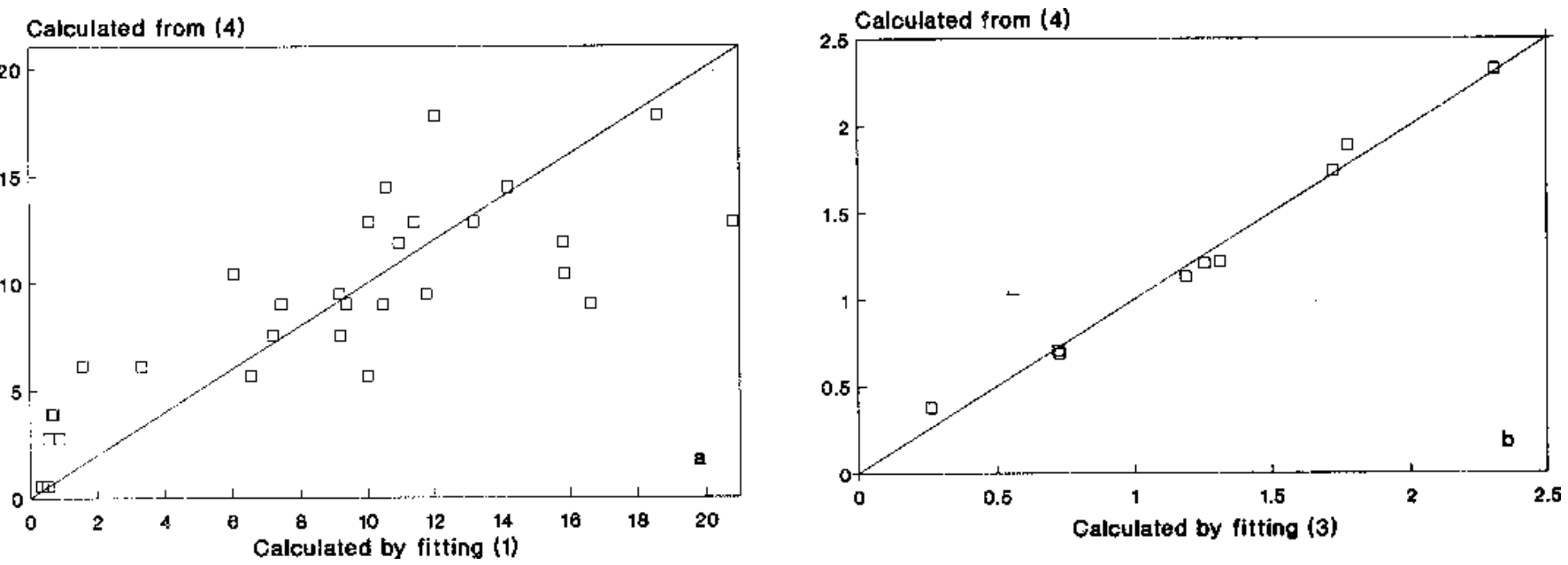

Fig. 8. Conductance for $\mathrm{CO}_{2}$ transfer obtained (a) for a cotton canopy by fitting Model [1] compared with predictions by Model [4], correlation coefficient $r=0.817$, and (b) for tomato leaf by fitting Model [3] compared with predictions by Model [2], $r=0.993$. Parameter values for Model [4]:

$\begin{array}{lll} & \text { Cotton } & \text { Tomato } \\ b_{1} & 3.228 & 0.23 \\ b_{2} & 0.0537 & 0.07 \\ b_{3} & 0.01 & 0.005\end{array}$


Eucalyptus grandis $\mathrm{Sw}$. calculated with this model combined with Farquhar's model of photosynthesis (Farquhar and von Caemmerer, 1982) were 0 to $0.01716 \mathrm{~m} \cdot \mathrm{s}^{-1}$ (Leuning, 1990). Values of canopy conductance from the experimental data for cotton in our study were within the same range. Conductance decreased linearly with increasing $\left[\mathrm{CO}_{2}\right]$ and increased exponentially with increasing temperature.

\section{THE COMPLETE MODEL}

The complete model for describing the dependence of cotton canopy $\mathrm{CO}_{2}$ exchange on light, $\left[\mathrm{CO}_{2}\right]$, and temperature contains seven parameters: $a_{1}, a_{2}, b_{1}, b_{2}, b_{3}, d_{1}$, and $d_{2}$ :

Parameter $a_{1}$ is the rate of increase of the canopy light-use efficiency with temperature, and $b_{2}$ shows the rate of increase of canopy conductance for $\mathrm{CO}_{2}$ transfer with temperature. Parameter $b_{1}$ defines the maximal $\tau_{c}$ value. Parameter $b_{3}$ indicates the rate of decrease of $\tau_{c}$ with increasing $\left[\mathrm{CO}_{2}\right]$. Parameter $d_{1}$ indicates the increase of photorespiration rate with increasing $\left[\mathrm{CO}_{2}\right]$. Parameters $a_{2}$ and $d_{2}$ are intercepts for corresponding relationships. This model can be used for closed cotton canopies because the experimental data on which the model is based were obtained for closed canopies 60 to 120 DAE. For other species and treatments, parameter values can be determined with the same technique as described above.

\section{CONCLUSIONS}

The empirical model for canopy $\mathrm{CO}_{2}$ exchange has been developed from experimental data on cotton in daylit chambers with controlled air temperature and $\left[\mathrm{CO}_{2}\right]$. The model contains seven parameters whose values can be determined with experimental data using the technique described above. The validation of the canopy $\mathrm{CO}_{2}$-exchange model can be effectively performed using the $\mathrm{F}$ test, analysis of residuals, and autocorrelation coefficient.

Every canopy light response curve for a particular combination of temperature and $\left[\mathrm{CO}_{2}\right]$ can be described adequately by a threeparameter hyperbolic model. The leaf light response curves need a four-parameter model for adequate description.

Canopy light-use efficiency, $\alpha_{c}$, and a photorespiration factor, $\beta$, increased linearly with increasing temperature. The dependence of these parameters on $\left[\mathrm{CO}_{2}\right]$ was not significant. Canopy and leaf conductance to $\mathrm{CO}_{2}$ transfer, $\tau_{c}$, strongly depended on temperature (exponentially) and $\left[\mathrm{CO}_{2}\right]$ (linearly).

Cotton canopy $\mathrm{CO}_{2}$-exchange rate increased with increasing $\left[\mathrm{CO}_{2}\right]$ at irradiance values higher than $200 \mathrm{~W} \cdot \mathrm{m}^{-2}$. The $\mathrm{CO}_{2}$ exchange rate showed a nonlinear increase with increasing temperature.

\section{Literature Cited}

Acock, B. 1991. Modeling canopy photosynthetic response to carbon dioxide, light interception, temperature, and leaf traits, p. 41-56. In: K.J. Boote and R.S. Loomis (eds.). Modeling crop photosynthesis-From biochemistry to canopy. Crop Sci. Soc. Amer. Spec. Publ. 19. Crop Sci. Soc. Amer., Amer. Soc. Agron, Madison, Wis.

Acock, B. and M.C. Acock. 1989. Calculating air leakage rates in controlledenvironment chambers containing plants. Agron. J. 81:619-623.
Acock, B., D.A. Charles-Edwards, D.J. Fitter, D.W. Hand, L.J. Ludwig, J. Warren Wilson, and A.C. Withers. 1978. The contribution of leaves from different levels within a tomato crop to canopy net photosynthesis: An experimental examination of two canopy models. J. Expt. Bot. 29:815-827.

Acock, B., V.R. Reddy, H.F. Hodges, D.N. Baker, and J.M. McKinion. 1985. Photosynthetic response of soybean canopies to full-season carbon dioxide enrichment. Agron. J. 77:942-947.

Ball, J.T., I.E. Woodrow, and J.A. Berry. 1987. A model predicting stomatal conductance and its contribution to the control of photosynthesis under different environmental conditions, p. 221-224. In: J. Biggins (ed.). Progress in photosynthesis research. vol. 4. Martinus Nijhoff, Dordrecht, The Netherlands.

Boote, K.J. and R.S. Loomis. 1991. The prediction of canopy assimilation, p. 109-140. In: K.J. Boote and R.S. Loomis (eds.). Modeling crop photosynthesis-From biochemistry to canopy. Crop Sci. Soc. Amer. Spec. Publ. 19. Crop Sci. Soc. Amer., Amer. Soc. Agron., Madison, Wis.

Denison, R.F. and R.S. Loomis. 1989. An integrative physiological model of alfalfa growth and development. Bul. Div. Agr. Natural Resources, Univ. of California, Oakland.

Evans, J.R. and G.D. Farquhar. 1991. Modeling canopy photosynthesis from the biochemistry of the $\mathrm{C}_{3}$ chloroplast, p. 1-16. In: K.J. Boote and R.S. Loomis (eds.). Modeling crop photosynthesis-From biochemistry to canopy. Crop Sci. Soc. Amer. Spec. Publ. 19. Crop Sci. Soc. Amer., Amer. Soc. Agron., Madison, Wis.

Farquhar, G.D. and S. von Caemmerer. 1982. Modelling of photosynthetic response to environmental conditions, p. 550-588. In: O.L. Lanhe, P.S. Nobel, C.B. Osmond, and H. Ziegler (eds.). Physiological plant ecology II. Encyclopedia of plant physiology new series. vol. 12B. Springer-Verlag, Berlin.

Gomez, K.A. and A.A. Gomez. 1983. Statistical procedures for agricultural research. 2nd ed. Wiley, New York.

Halfon, E. 1985. Is there a best model structure? III. Testing the goodness of fit. Ecol. Modelling 27:15-23.

Himmelblau, D.M. 1968. Process analysis by statistical methods. Wiley, New York.

Jarvis, P.G. and J.I.L. Morison. 1981. The control of transpiration and photosynthesis by the stomata, p. 247-279. In: P.G. Jarvis and T.A. Mansfield (eds.). Stomatal physiology. Cambridge Univ. Press, Cambridge, U.K.

Laisk, A. 1977. Kinetics of photosynthesis and photorespiration in $\mathrm{C}_{3}$ plants. Nauka, Moscow.

Leuning, R. 1990. Modelling stomatal behaviour and photosynthesis of Eucalyptus grandis. Austral. J. Plant Physiol. 17:159-175.

Mansfield, T.A., A.J. Travis, and R.G. Jarvis. 1981. Responses to light and carbon dioxide, p. 119-135. In: P.G. Jarvis and T.A. Mansfield (eds.). Stomatal physiology. Cambridge Univ. Press, Cambridge, U.K.

Marquardt, D.W. 1963. An algorithm for last-squares estimation on nonlinear parameters. Soc. Industrial Applied Mathematics J. 11:431-441.

Pachepsky, Ya.A., E.V. Mironrnko, R.V. Galiulin, and M.S. Sokolov. 1982. Statistical models of the dynamics of pesticides and their metabolites content in soils. Ecological Software 8. Acad. Sci. USSR, Pushchino.

Reddy, V.R., D.N. Baker, and H.F. Hodges. 1991. Temperature effects on cotton canopy growth, photosynthesis, and respiration. Agron. J. 83:699704.

Sage, R.F., T.D. Sharkey, and J.R. Seeman. 1989. Acclimation of photosynthesis to elevated $\mathrm{CO}_{2}$ in five $\mathrm{C}_{3}$ species. Plant Physiol. 89:590-596.

Sinclair, T.R. 1991. Canopy carbon assimilation and crop radiation-use efficiency dependence on leaf nitrogen content, p. 95-107. In: K.J. Boote and R.S. Loomis (eds.). Modeling crop photosynthesis-From biochemistry to canopy. Crop Sci. Soc. Amer. Spec. Publ. 19. Crop Sci. Soc. Amer., Amer. Soc. Agron., Madison, Wis.

Stanghellini, C. and J.A. Bunce. 1993. Response of photosynthesis and conductance to light, $\mathrm{CO}_{2}$, temperature, and humidity in tomato plants acclimated to ambient and elevated $\mathrm{CO}_{2}$. Photosynthetica 29:487-497.

Wetherald, R.T. 1989. Changes of temperature and hydrology caused by an increase of atmospheric carbon dioxide as predicted by general circulation models, p. 1-19. In: R.L. Wyman (ed.). Global climate change and life on earth. Routledge, Chapman and Hall, New York.

Wheeler, R.M., K.A. Corey, J.C. Sager, and W.M. Knott. 1993. Gas exchange characteristics of wheat stands in a closed, controlled environment. Crop Sci. 33:161-168. 